ARTICLE

https://doi.org/10.1038/s41467-019-08506-5

\title{
Evolution of the electrochemical interface in sodium ion batteries with ether electrolytes
}

Kaikai Li ${ }^{1,2,3}$, Jun Zhang ${ }^{1}$, Dongmei Lin ${ }^{3}$, Da-Wei Wang (1) ${ }^{4}$, Baohua Li ${ }^{5}$, Wei Lv ${ }^{5}$, Sheng Sun ${ }^{6}$, Yan-Bing He ${ }^{5}$, Feiyu Kang ${ }^{1,5}$, Quan-Hong Yang ${ }^{1,7}$, Limin Zhou ${ }^{2,3} \&$ Tong-Yi Zhang ${ }^{6}$

Ether based electrolytes have surfaced as alternatives to conventional carbonates allowing for enhanced electrochemical performance of sodium-ion batteries; however, the primary source of the improvement remains poorly understood. Here we show that coupling titanium dioxide and other anode materials with diglyme does enable higher efficiency and reversible capacity than those for the combination involving ester electrolytes. Importantly, the electrolyte dependent performance is revealed to be the result of the different structural evolution induced by a varied sodiation depth. A suit of characterizations show that the energy barrier to charge transfer at the interface between electrolyte and electrode is the factor that dominates the interfacial electrochemical characteristics and therefore the energy storage properties. Our study proposes a reliable parameter to assess the intricate sodiation dynamics in sodium-ion batteries and could guide the design of aprotic electrolytes for next generation rechargeable batteries.

\footnotetext{
${ }^{1}$ Shenzhen Environmental Science and New Energy Technology Engineering Laboratory, Tsinghua-Berkeley Shenzhen Institute (TBSI), Tsinghua University, Shenzhen 518055, China. ${ }^{2}$ Interdisciplinary Division of Aeronautical and Aviation Engineering, The Hong Kong Polytechnic University, Hong Kong, China. ${ }^{3}$ Department of Mechanical Engineering, The Hong Kong Polytechnic University, Hong Kong, China. ${ }^{4}$ School of Chemical Engineering, The University of New South Wales, Sydney 2052 NSW, Australia. ${ }^{5}$ Shenzhen Key Laboratory for Graphene-based materials and Engineering Laboratory for Functionalized Carbon Materials, Graduate School at Shenzhen, Tsinghua University, Shenzhen 518055, China. ${ }^{6}$ Materials Genome Institute, Shanghai University, 333 Nanchen Road, 200444 Shanghai, China. ${ }^{7}$ Nanoyang Group, State Key Laboratory of Chemical Engineering, School of Chemical Engineering and Technology, Tianjin University, 300072 Tianjin, China. These authors contributed equally: Kaikai Li, Jun Zhang. Correspondence and requests for materials should be addressed to Q.-H.Y. (email: qhyangcn@tju.edu.cn) or to L.Z. (email: mmlmzhou@polyu.edu.hk) or to T.-Y.Z. (email: mezhangt@ust.hk)
} 
S odium-ion batteries (SIBs) have attracted more attention in recent years particularly for large-scale energy storage due to the natural abundance of sodium compared to lithium ${ }^{1,2}$. However, their performance including specific capacity, rate capability, and cycle life are severely hindered by the larger diameter of sodium ions than lithium ions ${ }^{3,4}$, and as a result there have been extensive efforts in searching for suitable electrode materials, in particular on the anode side ${ }^{5,6}$. In order to improve the electrochemical performance of the present anode materials, modifying the electrolyte is an important and effective approach. Most commonly used non-aqueous electrolytes inevitably decompose forming a solid electrolyte interphase (SEI) on the anode materials because the operating voltage is lower than their stable voltage range. Conventional electrolytes in SIBs are formulated using ester-based solvents similar to those used in lithium-ion batteries (LIBs $)^{7,8}$, and these produce SEIs that are often reported to be not sufficiently stable and likely to cause severe polarization ${ }^{9}$. In this context, ether-based electrolytes are believed to be less useful in LIBs owing to inferior passivation on both anodes and cathodes, but they have recently been revived in SIBs because of their ability to trigger the highly reversible cointercalation of sodium ions with an ether solvent into graphite $\mathrm{e}^{10-14}$. The improved sodium storage performance has been observed on different anode materials like $\mathrm{CuS}$ nanosheets ${ }^{3}$, $\mathrm{ZnS}$ nanospheres ${ }^{11}$, bismuth ${ }^{15}$, and reduced graphene oxide $(\mathrm{rGO})^{9}$ when ester-based electrolytes are replaced with ether analogs. It is proposed that this improvement is due to the suppression of dissolved polysulfide intermediates ${ }^{3}$, faster $\mathrm{Na}^{+}$ transport, good electrode wettability ${ }^{11,15}$, and the formation of a thinner $\mathrm{SEI}^{9}$. Su et al. ${ }^{11}$ proved that $\mathrm{Na}$ ions can be easily absorbed on an ether-based solvent and there is a low energy barrier for $\mathrm{Na}$ ion diffusion in it, and Seh et al. ${ }^{16}$ proved that a glyme-based electrolyte (a typical type of ether-based electrolyte) is superior to an EC/DEC-based electrolyte (a typical ester-based electrolyte; here ethylene carbonate is denoted as EC and diethyl carbonate is denoted as DEC) for a $\mathrm{Na}$ metal anode due to the formation of low resistivity SEI, making a large advance on the research of ether-based electrolytes for SIBs. However, the interfacial electrochemical characteristics, especially charge transfer in different types of electrolyte has not yet been systematically investigated. A deeper understanding of the issue is urgently needed so as to clarify the intrinsic origin of the improvement produced by ether-based electrolytes in SIBs. This is a key point in the revival of this technology using an etherbased electrolyte ${ }^{17,18}$.

Selecting a typical and ideal anode material is crucial to address this issue and $\mathrm{TiO}_{2}$ is preferably chosen in this study considering the following points. Firstly, the sodiation of $\mathrm{TiO}_{2}$ results in the formation of an amorphous sodium titanate phase so that the structural evolution during sodiation can be easily detected $^{19-22}$. Secondly, the intercalation mechanism and the small volume change produced by pseudocapacitive sodium storage in amorphous sodium titanate ${ }^{23,24}$ also guarantee the formation of a mechanically stable interface between electrolyte and electrode, which is difficult to achieve in other anodes that involve large volume changes or conversion reactions upon sodiation. Thirdly, unlike the long flat plateau at $\sim 1.75 \mathrm{~V}$ vs $\mathrm{Li} / \mathrm{Li}^{+}$in lithium-ion batteries (LIBs), the operating potential of $\mathrm{TiO}_{2}$ in SIBs decreases to $0.005 \mathrm{~V}$, which inevitably results in the formation of SEI layer on the electrode ${ }^{25}$. Lastly, optimizing electrolyte is also promising to address the bottleneck of practical application of $\mathrm{TiO}_{2}$ anodes including low initial coulombic efficiency (ICE) and fast capacity decay ${ }^{18,26-28}$, although current efforts have mostly targeted the improvement of the electronic conductivity in $\mathrm{TiO}_{2} 29-33,34-36,37$. Further extending the knowledge and experience of above $\mathrm{TiO}_{2}$-based research to other metal and carbon- based anodes can better illustrate the generality and origin of ether-enhanced interfacial electrochemical characteristics.

In the present work, we investigate ether-induced interfacial electrochemical characteristics for SIBs by coupling anatase $\mathrm{TiO}_{2}$ with a diglyme-based electrolyte. Such a $\mathrm{TiO}_{2}$ anode shows excellent capacity retention and rate capability, compared to those coupled with an EC/DEC-based electrolyte. Insights into the structural evolution and sodiation dynamics obtained by in operando Raman, X-ray diffraction (XRD), and electrochemical kinetic studies reveal that the charge transfer characteristics of the electrolyte/electrode interface play a vital role in determining the performance, which is also confirmed for Sn, rGO, and CMK-3 anodes. Comprehensive X-ray photoelectron spectroscopy (XPS) analyses show that the SEI formed in different electrolytes is composed of different organic species and exhibits distinct composition changes along the SEI depth with more inorganic species in the inner region when formed in an ether-based electrolyte. This is the origin of the electrolyte-dependent sodiation dynamics and battery performance. Our results indicate a general and fundamental explanation of the improved electrochemical performance of different anodes for SIBs induced using an etherbased electrolyte. This study might suggest an avenue for the design of efficient electrolyte/electrode interfaces for improved performance of non-aqueous rechargeable batteries.

\section{Results}

Sodium ion storage performance. Rhombic anatase $\mathrm{TiO}_{2}$ nanocrystals were synthesized using a solvothermal technique similar to that reported elsewhere ${ }^{38}$. The average size of the nanocrystals was around $16 \mathrm{~nm}$ as shown in Supplementary Figures 1 and 2. Supplementary Figure 2b is a HRTEM image of an individual $\mathrm{TiO}_{2}$ nanocrystal, clearly showing the $\mathrm{TiO}_{2}$ anatase crystal lattice with (101) planes and a $d$-spacing of $0.35 \mathrm{~nm}$. The XRD pattern and Raman spectrum (Supplementary Figure $2 \mathrm{c}$ and d) confirm that the anatase $\mathrm{TiO}_{2}$ nanocrystals are monophasic (JCPDS 21-1272) with a high crystallinity. The SIB anode was prepared using these $\mathrm{TiO}_{2}$ nanocrystals $(70 \mathrm{wt} \%)$ as the active material, carbon black (15 wt\%) as the conductive agent, and polyvinylidene fluoride (PVDF) (15 wt\%) as the binder. Coin cells were then assembled using two different solvent-based electrolytes, i.e., $\mathrm{NaCF}_{3} \mathrm{SO}_{3}$ dissolved in $\mathrm{EC} / \mathrm{DEC}$ and $\mathrm{NaCF}_{3} \mathrm{SO}_{3}$ in diglyme. Figure la shows the discharge/charge voltage profiles of SIBs prepared with this $\mathrm{TiO}_{2}$ anode and the EC/DEC electrolyte, measured at current densities ranging from 0.1 to $2 \mathrm{Ag}^{-1}$. The voltage profiles are linear with no obvious plateau regions, which is different from the flat and prolonged voltage plateau observed in $\mathrm{LIBs}^{39}$. This indicates that the sodiation of $\mathrm{TiO}_{2}$ proceeds by a different mechanism from lithiation, which might indicate a single-phase Na-intercalation process ${ }^{40}$. As clearly demonstrated by others, the sodiation of anatase $\mathrm{TiO}_{2}$ is a solid-solution-like reaction ${ }^{21,41}$. The operation potential of these anatase nanocrystals as the SIB anode is averaged to be $\sim 0.8 \mathrm{~V}$, which is significantly lower than that for Li intercalation $(\sim 1.75 \mathrm{~V}$ vs. $\mathrm{Li} /$ $\left.\mathrm{Li}^{+}\right)^{39}$, making $\mathrm{TiO}_{2}$ more promising for practical applications. When EC/DEC is replaced by diglyme, a significant improvement is observed in the anode performance, as shown in Fig. 1b. For instance, the specific capacity at $0.2 \mathrm{~A} \mathrm{~g}^{-1}$ is improved from 114.8 to $199.4 \mathrm{mAh} \mathrm{g}^{-1}$. Increasing the current rate from 0.1 to $2 \mathrm{~A} \mathrm{~g}^{-1}$ causes a capacity loss in both cases, but it is more severe in the EC/DEC case (decreasing from 137.5 to $42.2 \mathrm{mAh} \mathrm{g}^{-1}$ ) than in diglyme (decreasing from 257.9 to $102.1 \mathrm{mAh} \mathrm{g}^{-1}$ ). It is also worth noting that using the diglyme-based electrolyte obviously improves the ICE of $\mathrm{TiO}_{2}$ as an SIBs anode, which is one of the critical issues for $\mathrm{TiO}_{2} \mathrm{SIB}$ anodes. As shown in Supplementary Figure 3, the ICE is as high as $69 \%$ in a diglyme-based electrolyte, 

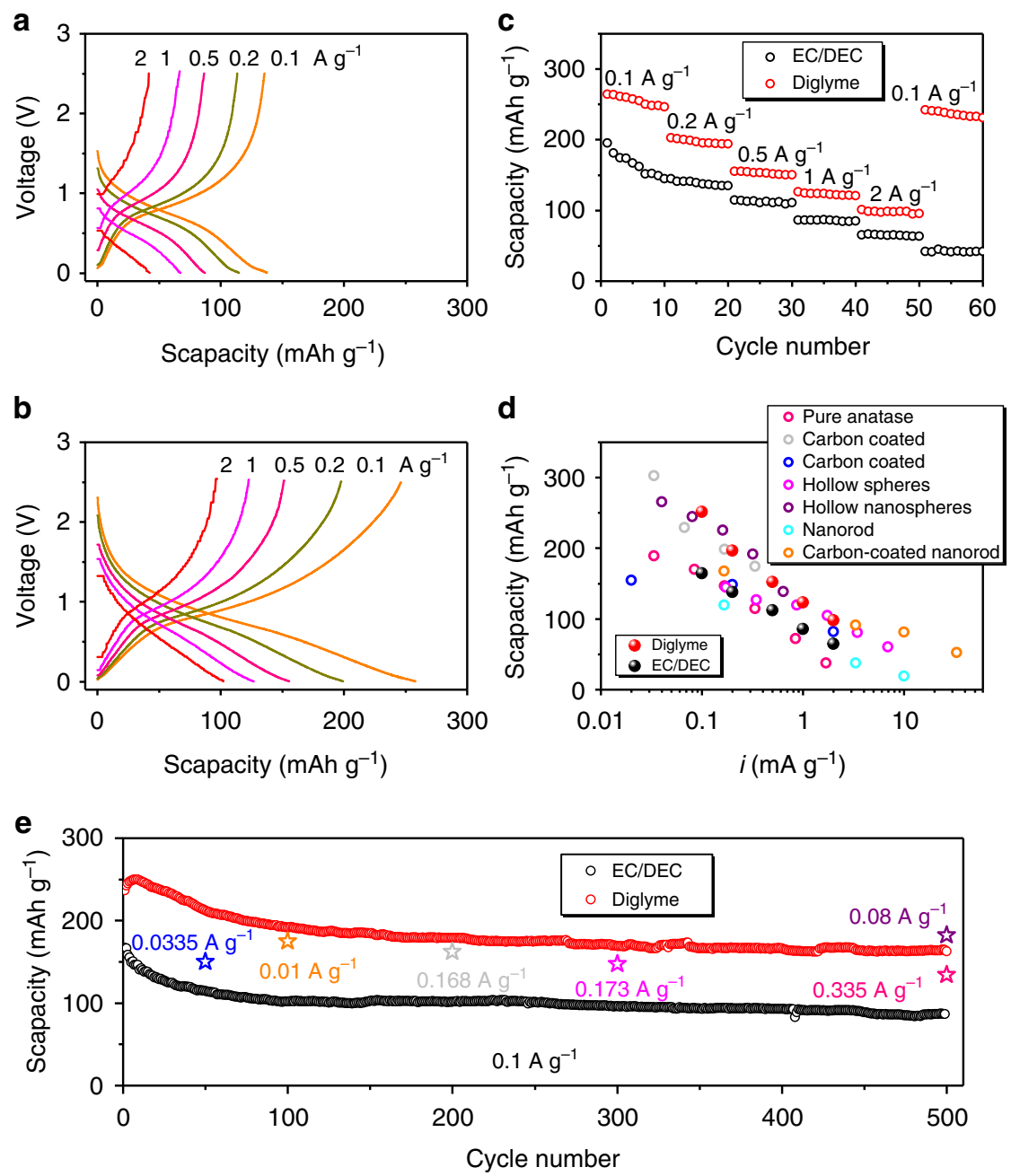

Fig. 1 Battery performance. a Voltage profiles of the $\mathrm{TiO}_{2}$ anode at different rates using the EC/DEC-based electrolyte (scapacity: specific capacity). b Voltage profiles of the $\mathrm{TiO}_{2}$ anode at different rates using the diglyme-based electrolyte. Note that the profiles at $0.1 \mathrm{Ag}^{-1}$ in $\mathbf{a}$ and $\mathbf{b}$ are for the third cycle while the others are for the first cycle at corresponding rates. c Rate performance. $\mathbf{d}$ Performance compared with anatase $\mathrm{TiO}_{2}$-based $\mathrm{SIB}$ anodes reported in the literature, i.e., pure anatase $\mathrm{TiO}_{2}{ }^{56}$, carbon-coated anatase ${ }^{57,58}$, hollow spheres ${ }^{23}$ and hollow nanospheres ${ }^{59}$, anatase nanorods ${ }^{60}$, and coated anatase nanorods ${ }^{60}$. e Cyclic performance at $0.1 \mathrm{~A} \mathrm{~g}^{-1}$, and comparison with cyclic performance reported in the literature

much higher than the $33 \%$ in an EC/DEC-based electrolyte, although a further increase is still needed for the real applications.

Figure $1 \mathrm{c}, \mathrm{d}$ shows the rate capabilities of the $\mathrm{TiO}_{2}$ anode using two different electrolytes. The cells using the diglyme-based electrolyte show an exceptional high rate capability, much higher than that for the EC/DEC system. Remarkable reversible capacities of $\sim 252,197,153,124$, and $99 \mathrm{mAh} \mathrm{g}^{-1}$ were recorded for the diglyme case at current rates of $0.1,0.2,0.5,1$, and $2 \mathrm{~A} \mathrm{~g}^{-1}$, respectively. The corresponding values for EC/DEC are only $\sim 165,139,113,86$, and $66 \mathrm{mAh} \mathrm{g}^{-1}$. When the current rate is decreased to $0.1 \mathrm{~A} \mathrm{~g}^{-1}$, the cell with diglyme retains its high capacity while the cell based on EC/DEC does not, indicating better reversibility when the diglyme-based electrolyte is used. Compared to the anatase $\mathrm{TiO}_{2}$ SIB anodes reported in the literature, the performance of the present $\mathrm{TiO}_{2}$ anode coupled with diglyme is among the best available. It is worth noting that the present $\mathrm{TiO}_{2}$ active materials are not carbon-modified or doped with other elements, implying a potential for further optimization by compositing with carbons or other elements. Both cells using diglyme and EC/DEC electrolytes have a quite stable long-life cyclic performance at $0.1 \mathrm{Ag}^{-1}$ as shown in Fig. 1e. But the absolute capacities of the cells using EC/DEC are much lower than those with the diglyme counterpart. After 500 cycles at $0.1 \mathrm{Ag}^{-1}$, a reversible capacity of $165 \mathrm{mAh} \mathrm{g}^{-1}$ was maintained for the cell based on the diglyme electrolyte, while the value was only $87 \mathrm{mAh} \mathrm{g}^{-1}$ for the case with EC/DEC. Our previous work ${ }^{9}$ demonstrated that carbon anodes such as rGO and CMK-3 showed much better efficiency and reversible capacity in the diglyme-based electrolyte than in EC/DEC system. Here, we further studied an Sn anode and found that the efficiency and reversible capacity in a diglyme-based electrolyte were superior to what was observed for EC/DEC (Supplementary Figure 4).

Structural analysis. To gain an insight into the excellent performance from the diglyme-based electrolyte and particularly into the Na-ion diffusion dynamics during sodiation/de-sodiation, we conducted in operando Raman spectroscopy (Supplementary Figure 5) and XRD (Supplementary Figure 8), and ex situ XRD to reveal the structural evolution, and scanned rate-dependent cyclic voltammetry $(\mathrm{CV})$ as well as temperature-dependent electrochemical impedance spectroscopy (EIS). The sodiation of anatase $\mathrm{TiO}_{2}$ is an intercalation reaction described as follows: the sodium 

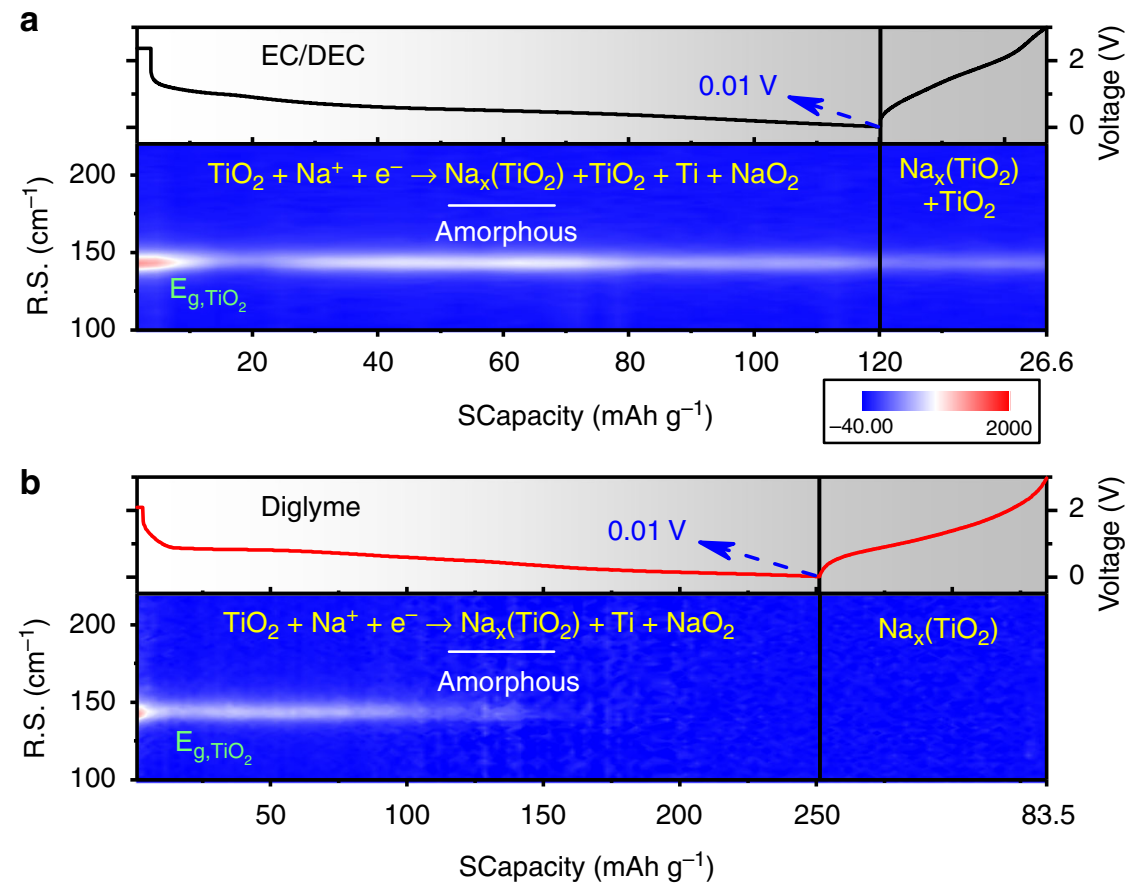

Fig. 2 In operando Raman spectroscopy. Raman spectra of the $\mathrm{TiO}_{2}$ anode during the first cycle of electrochemical sodiation/de-sodiation at a rate of 100 $\mathrm{mA} \mathrm{g}^{-1}$ (R.S.: Raman shifts), a using the EC/DEC-based electrolyte and $\mathbf{b}$ using the diglyme-based electrolyte ${ }^{21}$

is intercalated into the $\mathrm{TiO}_{2}$ lattice, distorts the lattice, and partially reduces the $\mathrm{TiO}_{2}$ to form metallic titanium, sodium oxide, and amorphous sodium titanate ${ }^{21}$, which acts as the host for the $\mathrm{Na}$ ion storage in the following cycles. Taking the above mechanism into consideration, complete sodiation of $\mathrm{TiO}_{2}$ results in the disappearance of the Raman bands of crystalline $\mathrm{TiO}_{2}$, which will not reappear after de-sodiation. As shown in Fig. 2b, the Raman spectra evolution characteristics of the $\mathrm{TiO}_{2}$ anode coupled with a diglyme-based electrolyte during the first cycle conform to this mechanism. In sharp contrast, when using the EC/DEC-based electrolyte, the $\mathrm{TiO}_{2}$ cannot be fully sodiated even when the voltage is $0.01 \mathrm{~V}$ in the first cycle, as shown in Fig. 2a where the Raman signal of $\mathrm{TiO}_{2}$ can still be observed, indicating a lower accessible capacity than when using diglyme in the first cycle, and only after $\sim 4$ cycles is the $\mathrm{TiO}_{2}$ completely transformed to the amorphous phase (Supplementary Figure 6). This incomplete sodiation of anatase $\mathrm{TiO}_{2}$ has also been observed in an EC/ PC (propylene carbonate)-based electrolyte ${ }^{42}$. The ex situ XRD results (Supplementary Figure 7) further prove the amorphization of the $\mathrm{TiO}_{2}$ during the first discharge in the diglyme-based electrolyte and the incomplete sodiation in the EC/DEC-based electrolyte. Ex situ XRD results of the Sn anode (Supplementary Figure 10) show the formation of the $\mathrm{Na}_{x} \mathrm{Sn}$ phase when discharged to $0.1 \mathrm{~V}$ in the diglyme-based electrolyte, which is not observed for the EC/DEC case. The in operando Raman spectroscopy and XRD (Supplementary Figure 9) along with the ex situ XRD results show that the sodiation of $\mathrm{TiO}_{2}$ and $\mathrm{Sn}$ is much easier in the diglyme-based electrolyte than in the EC/ DEC-based electrolyte. In our previous work $^{9}$, we showed that carbon materials like rGO and CMK-3 can be sodiated to a higher extent in the diglyme-based electrolyte than in the EC/DEC-based electrolyte.

Dynamic analysis. To reveal the true nature of the polarization at the $\mathrm{TiO}_{2}$ working electrode, we designed a coin cell-type 3-electrode setup (Supplementary Figure 12) and performed scan rate- dependent CV measurements, by which the effect at the $\mathrm{Na}$ counter electrode was eliminated. The $\mathrm{CV}$ results obtained from these tests are quite similar to those observed in the 2-electrode measurements (Supplementary Figure 11), as shown in Fig. 3, except for the smaller polarizations. It can be seen from Fig. $3 \mathrm{c}$ that the $\mathrm{TiO}_{2}$ working electrode coupled with the EC/DEC-based electrolyte has a much higher polarization than when coupled with the diglyme-based electrolyte, and the polarization becomes more severe as the scan rate increases. The potential polarization with an increased scan rate is extremely small in the case of diglyme, indicating quite favorable sodiation dynamics of the $\mathrm{TiO}_{2}$ electrode. Additionally, $\mathrm{CV}$ shows that the sodium storage of $\mathrm{TiO}_{2}$ is controlled by both capacitance and diffusion, and using the diglyme-based electrolyte increases the contribution from capacitance and facilitates the rapid (de)intercalation of sodium ions. This is very similar to that observed in graphene-modified $\mathrm{TiO}_{2}$ where the polarization decreases ${ }^{43}$ and the $\mathrm{Na}$ ion intercalation pseudocapacitive process increases ${ }^{24}$.

The total charge stored in a CV scan can be separated into faradaic contributions from $\mathrm{Na}$-ion intercalation and pseudocapacitance, and a non-faradaic contribution from the double layer effect that depends on the surface area ${ }^{44}$. These capacitive effects (pseudo-capacitance and double layer charging) can be distinguished from $\mathrm{Na}$-ion intercalation by analyzing the $\mathrm{CV}$ data at different sweep rates according to the relationship between the measured current $(I)$ and the scan rate $(v)^{45}$ :

$$
I=a v^{b}
$$

and the $b$-value is determined by the slope of the $\log (v)-\log (I)$ plot. In particular, a $b$-value of 0.5 indicates total diffusioncontrolled behavior, whereas 1.0 indicates a capacitive process. The $\log (v)-\log \left(I_{\mathrm{p}}\right)$ plots and corresponding $b$-values are shown in Fig. $3 \mathrm{~d}$ (note that here we use the peak current $I_{\mathrm{p}}$ rather than the current $I$ at a given potential because of the large polarization), showing that in both cases the (de)sodiation is a combination of capacitance and diffusion. However, the $b$-values in the EC/DEC 

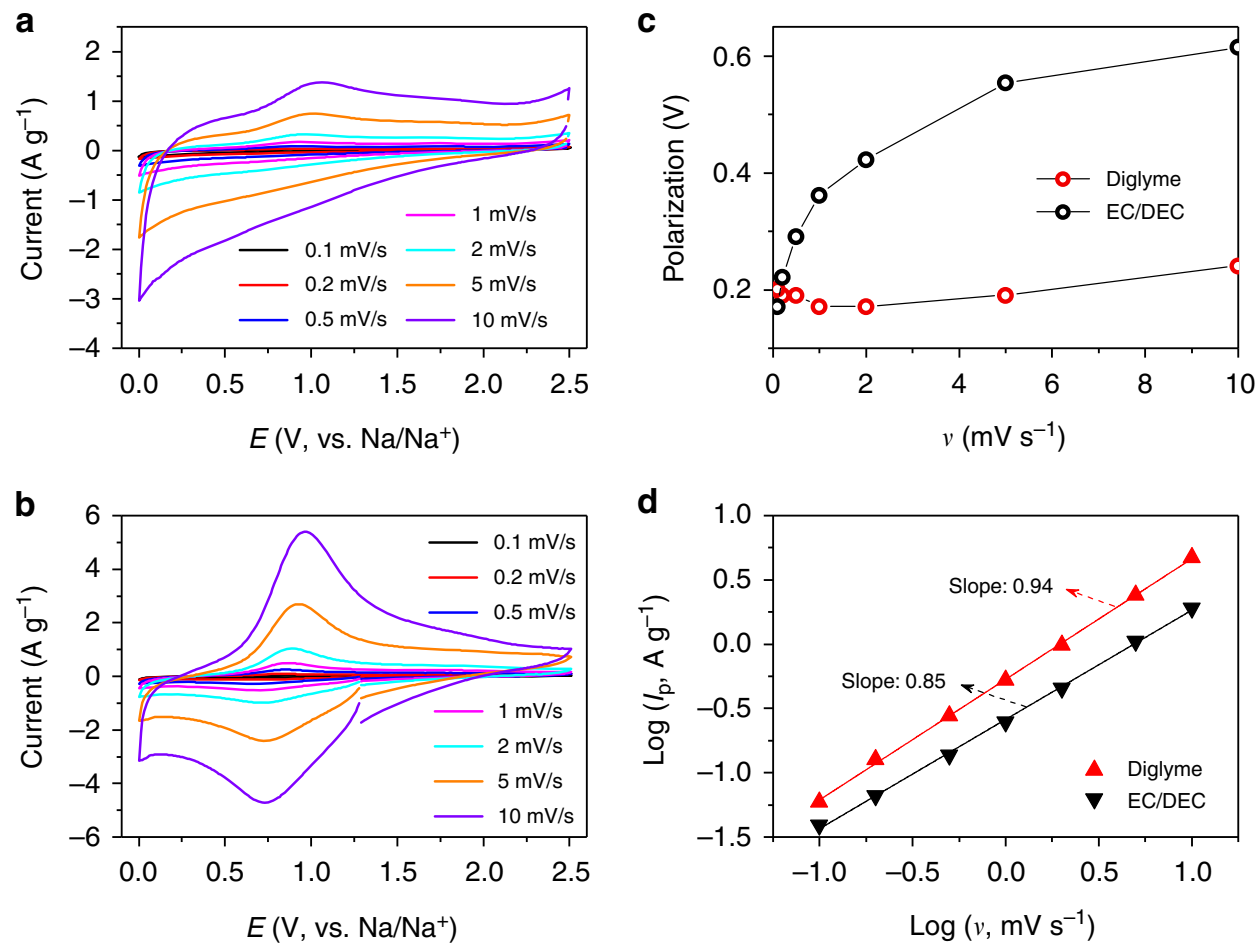

Fig. 3 Scan rate-dependent cyclic voltammetry (CV) from the 3-electrode tests (see the experimental setup in Supplementary Figure 12). a, b CV curves of the $\mathrm{TiO}_{2}$ anode at different scan rates with the EC/DEC-based electrolyte (a) and the diglyme-based electrolyte (b). c Separation (potential polarization) between the cathodic and anodic peaks in the $C V$ curves as a function of scan rate. $\mathbf{d} b$-values (slopes) obtained from the current peaks, $I_{p}=a v^{b}$, of the $C V$ curves

case are smaller than in the case of diglyme, meaning that for the EC/DEC the (de)sodiation is more diffusion-controlled and has slower diffusion kinetics than with diglyme. When using diglyme, a higher contribution of capacitive charge causes an increased intercalation pseudocapacitive behavior of $\mathrm{Na}^{+}$in the electrode (considering the double layer charging is sensitive to the surface area and thus is the same no matter the electrolyte), which contributes to the excellent rate capability and high capacity ${ }^{24}$.

The increased intercalation pseudo-capacitance triggered by the diglyme-based electrolyte indicates faster sodium ion diffusion and electron transport across the whole cell. To gain more fundamental insight into the faster dynamics, we conducted temperature-dependent EIS to examine the dynamic properties (the resistance and activation energy $E_{\mathrm{a}}$ ) of individual components in the cell system. According to Barsoukov's model ${ }^{46}$, the sodium ions diffuse across the liquid electrolyte (LE) and SEI layer, followed by a charge transfer process at the SEI/electrode interface and diffusion inside the electrode material. Here, we assume an SEI/electrode interface extending from the SEI layer to the electrode (as illustrated in Supplementary Figure 14). Different resistances and activation energies are involved. The resistances can be determined by fitting the EIS spectra, and the activation energies can be determined by fitting the temperaturedependent resistances. Figure $4 \mathrm{a}, \mathrm{b}$, respectively, shows the temperature-dependent EIS spectra of 2-electrode cells assembled using EC/DEC-based and diglyme-based electrolytes after 10 discharge-charge cycles at a rate of $100 \mathrm{~mA} \mathrm{~g}^{-1}$. Two semicircles and a straight line are identified in all these spectra, and in order to assign them, we compared the EIS spectra measured using both 2-electrode and 3-electrode setups (Supplementary Figure 13). It was found that the small semicircle at higher frequencies observed in the 2-electrode study almost disappears in the 3electrode study, which implies that the first semicircle at higher frequencies in the 2-electrode study includes the information of the SEI at the Na counter electrode. The second semicircle at lower frequencies in the 2-electrode study is very similar to the semicircle observed in the 3-electrode study. The DC-bias current-dependent EIS study using the 3-electrode setup confirms that this semicircle may be assigned to the charge-transfer process (Supplementary Figure 13a). Therefore, in the following discussion, we use the 2-electrode EIS study. The Arrhenius plots in Fig. $4 \mathrm{c}$ and data in Supplementary Table 2 represent the individual contributions of the solid electrolyte interphase $R_{\mathrm{SEI}}$ and the charge transfer resistance $R_{\mathrm{ct}}$, obtained from data fitting the temperature-dependent impedance spectra based on the equivalent circuit given in Supplementary Figure 14. For both the SEI and the SEI/electrode interface, an Arrhenius equation is used to determine the activation energies ${ }^{47}$ :

$$
\sigma T=A \exp \left(-E_{\mathrm{a}} / k_{\mathrm{B}} T\right) .
$$

Here, $A$ is the pre-exponential factor, $E_{\mathrm{a}}$ is the apparent activation energy for ion transport, $k_{\mathrm{B}}$ is the Boltzmann constant, $\sigma$ is the ionic conductivity, and $T$ is the absolute temperature. As expected, transport across the SEI/electrode interface has higher activation energy $\left(E_{\mathrm{a}, \mathrm{ct}}\right)$ than that across the SEI layer $\left(E_{\mathrm{a}, \mathrm{SEI}}\right)$ for both cases. When the EC/DEC-based electrolyte is used, the activation energy across the interface $\left(E_{\mathrm{a}, \mathrm{ct}, \mathrm{EC} / \mathrm{DEC}}\right)$ is the highest with a value of $\sim 410 \mathrm{meV}$ (which is very close to the value of $\sim 400 \mathrm{meV}$ from the 3-electrode EIS study, as shown in Supplementary Figure 13b, c and Supplementary Table 1, further verifying the effectiveness of the analysis in the 2-electrode study), and is higher by a factor of 2.4 than the corresponding value for the diglyme-based electrolyte. This means that at any temperature, transport of $\mathrm{Na}$ ions is faster across the SEI/electrode interface formed in diglyme than that formed in EC/DEC. The activation energy of $\mathrm{Na}^{+}$diffusion in the SEI layer $E_{\mathrm{a}, \mathrm{SEI}}$ is almost the same for the two cases. This is probably due to the fact that 

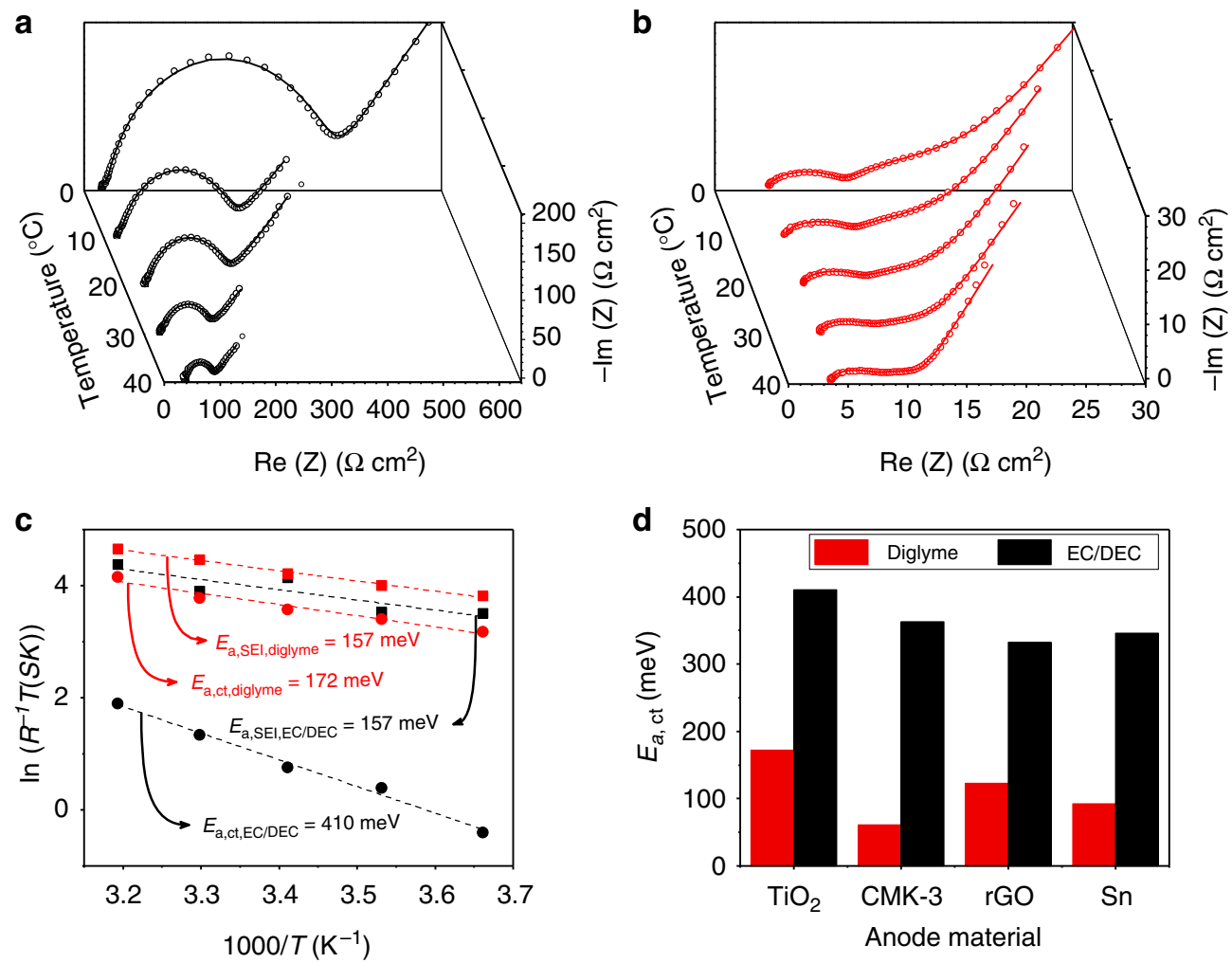

Fig. 4 Electrochemical impedance spectroscopy analysis after ten discharge-charge cycles. a, b Temperature-dependent $\mathrm{Ny}_{1}$ quist plots of the $\mathrm{TiO}_{2}$ anode for the EC/DEC-based electrolyte (a) and the diglyme-based electrolyte (b). c Arrhenius plot of the resistance contributions of the solid electrolyte interphase $R_{\mathrm{SEl}}$ and the charge transfer resistance $R_{\mathrm{ct}}$, with the derived activation energies $E_{\mathrm{a}, \mathrm{SEl}}$ and $E_{\mathrm{a}, \mathrm{ct}}$ for the $\mathrm{TiO}_{2}$ anode in the two electrolytes. d Comparison of the charge transfer energy barriers in the diglyme-based electrolyte and EC/DEC-based electrolytes for various electrode materials

$\mathrm{Na}^{+}$diffuses in the SEI layer by hopping migration and the activation energy for this is not significantly different in different SEI compositions ${ }^{48,49}$. It is also worth noting that the interfacial ionic conductivity in the diglyme-based system is much higher than that in the EC/DEC-based system, which implies a major effect of the use of different solvent-based electrolytes in SIBs. If transport through the SEI/electrode interface is sluggish, this interfacial resistance will have a detrimental effect on the rate capability ${ }^{47}$. This finding provides crucial insight into the improved interfacial characteristics induced by ether-based electrolytes, which is also demonstrated for other electrode materials, as shown in Fig. 4d. We also examined the temperature-dependent EIS of a CMK-3 anode (Supplementary Figure 15 and Table 3), an rGO anode (Supplementary Figure 16 and Table 4), and an Sn anode (Supplementary Figure 17 and Table 5) after cycling. In all cases, the charge transfer energy barrier $\left(E_{\mathrm{a},}, \mathrm{ct}\right)$ across the interface in the EC/DEC-based electrolyte is much higher than that in the diglyme-based electrolyte, by a factor of around 6 for a CMK-3 anode, 2.7 for an rGO anode, and 4 for an Sn anode.

SEI analysis. SEM examination of the electrode surface showed that an SEI had formed after cycling (Supplementary Figure 18). It seems that the formation of the SEI in a diglyme-based electrolyte is more uniform than that formed in an EC/DECbased electrolyte. We therefore carried out XPS to examine the SEIs formed in the two electrolytes, as shown in Fig. 5a-d. XPS depth profiling was done using Ar ion sputtering. As shown in Supplementary Figure 19, C, O, F, and $\mathrm{Na}$ signals were detected on the electrode surface in both cases and also at different etching depths. Figure $5 \mathrm{a}$ shows the elemental compositions of the SEI layer at different depths obtained by quantitative analysis of the XPS spectra. The most significant feature is that in the SEI formed in the diglyme-based electrolyte, the atomic fraction of $\mathrm{C}$ decreases distinctly with increasing etching depth $(\sim 28 \%$ at the surface and $\sim 5 \%$ at $23 \mathrm{~nm}$ depth$)$, while the atomic fraction of $\mathrm{Na}$ shows a completely opposite trend, and the atomic fraction of $\mathrm{O}$ increases slightly with etching depth. This means that the organic species are mainly distributed near the surface while the interior of the SEI is mainly composed of inorganic species. Although a slight decrease in the atomic fraction of $\mathrm{C}$ in the SEI formed in the EC/DEC-based electrolyte with etching depth is also observed, its value is much higher than with the diglyme counterpart. This indicates that there are more organic species in the SEI formed in the EC/DEC-based electrolyte and they are spread over the whole thickness of the SEI. Analyses of the Na Auger Parameter confirms these conclusions (Supplementary Figure 21 and Supplementary Table 6$)^{50}$. The inorganic species are generally localized and remain in a stable thin layer during cycling, leading to a low charge transfer resistance and energy barrier ${ }^{16,49}$. The presence of organic products, which are usually porous, makes the SEI much thicker ${ }^{16}$, leading to a much higher charge transfer resistance and energy barrier.

The SEI composition was also analyzed by high-resolution XPS using a $\mathrm{Mg} \mathrm{X}$-ray source. First, we analyzed the composition of the SEI formed in the diglyme-based electrolyte (Fig. 5d, Supplementary Figures 22-26 and Supplementary Table 7). The $\mathrm{C} 1 \mathrm{~s}$ spectrum was fitted using four peaks with binding energies of $\sim 284.9 \mathrm{eV}(\mathrm{C}-\mathrm{C}), \sim 286.0 \mathrm{eV}(\mathrm{C}-\mathrm{O}), \sim 289.9 \mathrm{eV}(\mathrm{O}-\mathrm{C}=\mathrm{O})$, and $\sim 292.0 \mathrm{eV}\left(-\mathrm{CF}_{2}-\right)$, which are consistent with sodium alkoxides $\left(\mathrm{RCH}_{2} \mathrm{ONa}\right)$ being the main reduction products of diglyme and $\mathrm{Na}_{2} \mathrm{CO}_{3}$ and $\mathrm{PVDF}^{9,16,50}$. The $\mathrm{O}$ 1s spectrum contained three peaks at $\sim 532.6 \mathrm{eV}(\mathrm{R}-\mathrm{O}-\mathrm{Na}), \sim 531.1 \mathrm{eV}$, and $\sim 530.0 \mathrm{eV}$ 
a
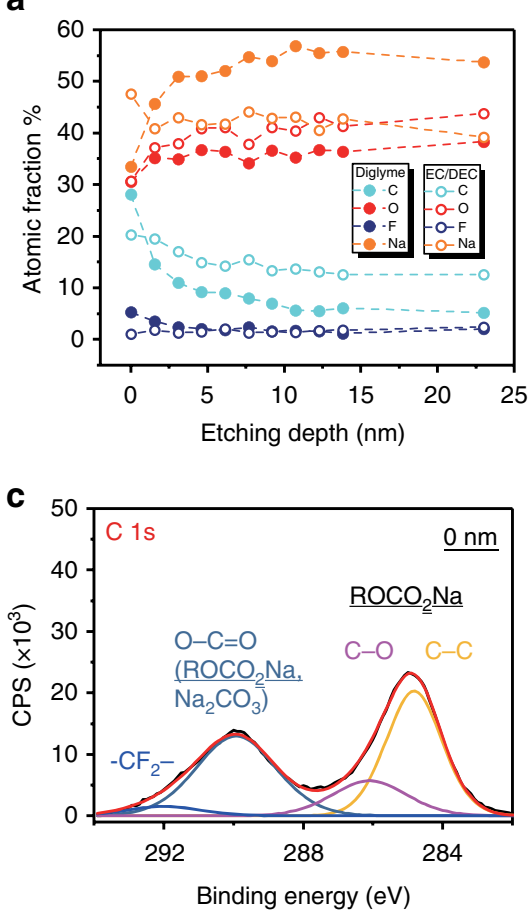

b

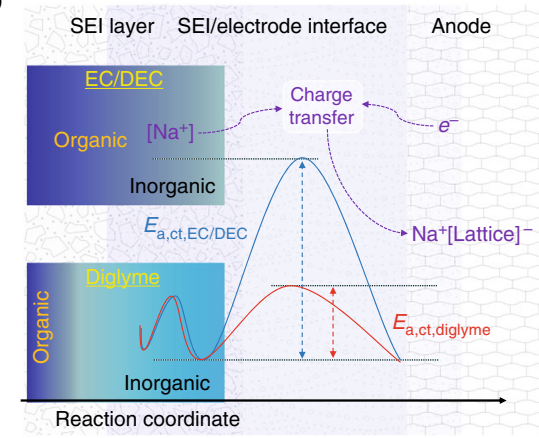

d

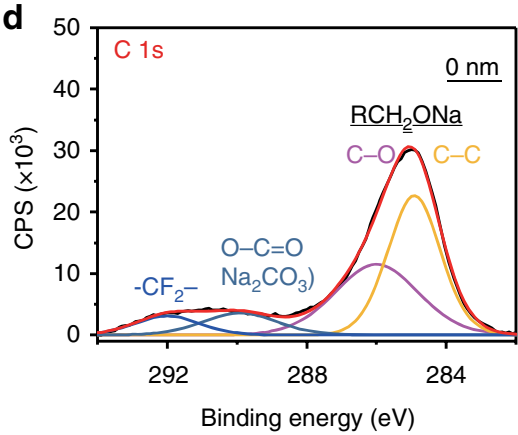

Fig. $5 \mathrm{SEI}$ chemistry and the charge transfer process. a The atomic fractions of C, O, F, and Na as a function of SEI depth, calculated from the XPS spectra depth profiling (Supplementary Figure 19). b Schematic of the SEl compositions formed in different electrolytes and a comparison of the charge transfer energy barriers. $\left[\mathrm{Na}^{+}\right]$means that the $\mathrm{Na}^{+}$may be solvated. There is a smaller amount of organic species in the SEl formed in the diglyme-based electrolyte and the inner part of the SEl is mainly composed of inorganic species. c XPS C 1s spectrum before etching in the EC/DEC-based electrolyte. d XPS C 1s spectrum before etching in the diglyme-based electrolyte

(Na-O-Ti), belonging to $\mathrm{RCH}_{2} \mathrm{ONa}, \mathrm{Na}_{2} \mathrm{CO}_{3}$, and $\mathrm{Na}_{x} \mathrm{TiO}_{2}$, respectively. The $\mathrm{O} 1 \mathrm{~s}$ spectrum change with etching depth also proves that the organic species decrease in the inner region of the SEI (Supplementary Figure 24a-c). The F 1s spectrum showed a peak at $\sim 684.9 \mathrm{eV}(\mathrm{Na}-\mathrm{F})$ and the $\mathrm{Na}$ 1s spectrum showed a peak at $\sim 1072.2 \mathrm{eV}(\mathrm{Na}-\mathrm{F}, \mathrm{Na}-\mathrm{O})$, indicating the existence of $\mathrm{NaF}$ and other sodium compounds $\left(\mathrm{RCH}_{2} \mathrm{ONa}, \mathrm{Na}_{2} \mathrm{CO}_{3}\right)$. Overall, we concluded that the SEI formed in the diglyme-based electrolyte contains both organic $\left(\mathrm{RCH}_{2} \mathrm{ONa}\right)$ and inorganic $\left(\mathrm{Na}_{2} \mathrm{CO}_{3}, \mathrm{NaF}\right)$ components. In the case of the EC/DEC-based electrolyte, we saw distinct XPS peaks corresponding to sodium alkyl carbonate $\left(\mathrm{ROCO}_{2} \mathrm{Na}\right)$ and inorganic products $\left(\mathrm{Na}_{2} \mathrm{CO}_{3}, \mathrm{NaF}\right)$, as shown in Fig. 5c, Supplementary Figures 22-26, and Supplementary Table 8 (refs. $9,16,50-54)$. Therefore, in addition to the distinct composition change along the SEI depth, there is also a difference between the SEIs formed in the two electrolytes because of the organic components formed by the decomposition of the different solvents, which is consistent with what is found in SIB Bi electrodes ${ }^{15}$. It has been reported that sodium alkoxides $\left(\mathrm{RCH}_{2} \mathrm{ONa}\right)$ ensure fast $\mathrm{Na}^{+}$transport and are essential for the interfacial stability of the Bi electrode ${ }^{15}$. First-principles calculations conducted by $\mathrm{Su}$ et al. demonstrated that an ether-based solvent reduces the energy barrier for sodium-ion diffusion and thus improves the electrochemical performances ${ }^{11}$. It is reasonable to deduce that the $\mathrm{RCH}_{2} \mathrm{ONa}$ also reduces the energy barrier for sodium-ion diffusion. The inorganic species in the SEI generally have low $\mathrm{Na}^{+}$diffusion activation energies (e.g., the activation energy for $\mathrm{NaF}$ is $\sim 100-150 \mathrm{meV}^{49}$ ). Combined with the above dynamic analysis, we conclude that the different SEI chemistries lead to the huge difference in the electrochemical performance of the two different solvent-based electrolytes by modifying the resistance of the SEI/electrode interfaces and the transport of $\mathrm{Na}^{+}$and electrons in them.

\section{Discussion}

The dynamic properties of the SEI/electrode interface play a vital role in the sodium storage. Modification of this interface can be achieved by changing the SEI chemistry, which depends on whether an ether-based or an ester-based electrolyte is used. But how the SEI chemistry works behind-the-scenes has not yet been fully determined, and undoubtedly needs further in situ experimental investigation and theoretical analysis. To support the governing role of the SEI/electrode interface, we measured the electrochemical performance and analyzed the sodiation dynamics of an anatase $\mathrm{TiO}_{2}$ anode composed of $84 \mathrm{~nm}$ nanocrystals (Supplementary Figure 26). First, as shown in Supplementary Figure 27, this anode shows similar voltage profiles to those of the $16 \mathrm{~nm} \mathrm{TiO}_{2}$ nanocrystal anode but has relatively lower specific capacities in both the EC/DEC-based and diglymebased electrolytes, with the capacity in the latter being higher than in the former, similar to what is observed for the $16 \mathrm{~nm}$ nanocrystal anode. We hypothesize that the reasons for the inferior capacity of $84 \mathrm{~nm}$ nanocrystal material are the high sodium diffusion energy barrier and relatively small crystal surface area. Interestingly, dynamic analysis shows that in the diglyme-based electrolyte, as shown in Supplementary Figure 28, 29 and Table 9, the activation energies of sodium diffusion through the SEI layer as well as the SEI/electrode interface are quite close for the two materials, meaning almost the same energy barriers for sodium transport and charge transfer. On the one hand, this indicates that the activation energy for charge transfer at the electrolyte/ electrode interface is inherent to the nature of the interface and is almost independent of particle size. On the other hand, the large surface area is one of the reasons accounting for the better performance of the $16 \mathrm{~nm}$ than the $84 \mathrm{~nm}$ material, because a larger surface area results in a correspondingly larger interface area and higher electrochemical reactivity. 
Apart from the electrolyte/electrode interfacial properties, solvent wettability is another parameter that may influence the sodium ion surface diffusion kinetics. Better solvent wettability is beneficial for improving the rate performance because of better ion availability as a result of the easier penetration of the electrolyte, since the surface ion availability may play an essential role in providing sufficient $\mathrm{Na}$ ions for intercalation into the $\mathrm{TiO}_{2}{ }^{55}$. The solvent wettability is measured by the contact angle. As shown in Supplementary Figure 30, both the EC/DEC-based and diglyme-based electrolytes effectively spread over the electrode surface composed of $16 \mathrm{~nm} \mathrm{TiO}_{2}$ nanocrystals, super P and PVDF within $5 \mathrm{~s}$, suggesting that the electrolyte wettability is not a decisive factor that influences the battery performance of the $16 \mathrm{~nm} \mathrm{TiO}_{2}$ anode. While for the electrode consisting $84 \mathrm{~nm}$ nanocrystals, the wettability is distinctly different for the two electrolytes (Supplementary Figure 30) with that of the diglymebased electrolyte being better than that of the EC/DEC-based electrolyte. Except for the larger electrochemical active surface area, the better electrolyte wettability should also contribute to the superior electrochemical performance of the $16 \mathrm{~nm} \mathrm{TiO}_{2}$ compared to the $84 \mathrm{~nm} \mathrm{TiO}_{2}$.

In summary, as a superior model anode, the $16 \mathrm{~nm}$ nanocrystal anatase $\mathrm{TiO}_{2}$ coupled with the diglyme-based electrolyte shows a reversible capacity of $257.9 \mathrm{mAh} \mathrm{g}^{-1}$ at $100 \mathrm{~mA} \mathrm{~g}^{-1}$ and more than $100 \mathrm{mAh} \mathrm{g}^{-1}$ at $2000 \mathrm{~mA} \mathrm{~g}^{-1}$, both of which are much better than in the EC/DEC-based electrolyte and are among the best values ever reported for anatase-based anodes for SIBs. The Sn, rGO, and CMK-3 anodes also show superior $\mathrm{Na}^{+}$ storage performance in the diglyme-based electrolyte than in the EC/DEC-based electrolyte. In operando Raman spectra and XRD show that the ether-based electrolyte facilitates the sodiation-induced structural transitions of the $\mathrm{TiO}_{2}$ and $\mathrm{Sn}$ anodes. We have also shown that charge transfer dynamics at the SEI/electrode interface play a crucial role in the rate-cycling performance and are nearly size-independent. Charge transfer has an energy barrier of $172 \mathrm{meV}$ for the interface formed in the diglyme-based electrolyte (1.4 times lower than for the interface in the EC/DEC-based electrolyte) for the $\mathrm{TiO}_{2}$ anode, providing faster charge transfer across the electrolyte/electrode interface. Significant reductions in the charge transfer energy barrier are also demonstrated in Sn, CMK-3, and rGO electrodes when the EC/DEC-based electrolyte is replaced by the diglymebased electrolyte. The faster dynamics increase the $\mathrm{Na}^{+}$intercalation pseudocapacitive behavior, which is highly beneficial to fast charge storage and long-term stability. The chemistry and composition distribution in the SEI layer are of great relevance for the charge transfer, with the organic species formed in the ether-based electrolyte together with the inorganic species favoring the sodiation dynamics. The information obtained in this work provides a general framework for understanding the origin of the extraordinary performance and improved interfacial characteristics of an ether-based electrolyte for SIB anodes, and can guide the future design and matching between non-aqueous electrolytes and novel electrode materials for rechargeable batteries.

\footnotetext{
Methods

Synthesis of anatase $\mathrm{TiO}_{2}$ nanocrystals. Titanium(IV) butoxide (TB, 97\%), oleic acid (OA, 90\%), oleylamine (OM, 70\%), and absolute ethanol were purchased form Aldrich. All chemicals were used as received. The synthesis of the $\mathrm{TiO}_{2}$ nanocrystals was accomplished using a solvothermal method. Typically, $5 \mathrm{mmol}$ TB was added to a mixture of $25 \mathrm{mmol} \mathrm{OA}, 25 \mathrm{mmol} \mathrm{OM}$, and $100 \mathrm{mmol}$ absolute ethanol. The mixture was stirred in a $40-\mathrm{mL}$ Teflon cup for $10 \mathrm{~min}$ before being transferred into a $100-\mathrm{mL}$ Teflon-lined stainless-steel autoclave containing $20 \mathrm{~mL}$ of a mixture of ethanol and water $\left(96 \%\right.$ ethanol, v/v). The system was then heated at $180^{\circ} \mathrm{C}$ for $18 \mathrm{~h}$. The white $\mathrm{TiO}_{2}$ nanocrystal precipitates obtained were washed several times
}

with ethanol and then dried at room temperature before being heated at $350^{\circ} \mathrm{C}$ for $5 \mathrm{~h}$ in air.

Materials characterization. Transmission electron microscope (TEM) images and selected area electron diffraction (SAED) patterns of the $\mathrm{TiO}_{2}$ nanocrystals were obtained using a JEOL $2010 \mathrm{~F}$ transmission electron microscope operated at $200 \mathrm{kV}$. Raman spectra were collected using a Raman spectrometer (LabRAM HR spectrometer, Horiba) with a 532.05-nm Ar-ion laser. XRD patterns were recorded over the range $20-80^{\circ}$ on a Rigaku diffractometer equipped with a $\mathrm{Cu} \mathrm{K}$ radiation source operated at $40 \mathrm{kV}$ and $120 \mathrm{~mA}$.

Cell assembly and testing. The active materials (70 wt\%) were homogeneously mixed with conductive carbon black (15 wt\%) and PVDF (15 wt\%) in NMP to form a slurry, which was stirred for $6 \mathrm{~h}$ and coated onto a $\mathrm{Cu}$ foil. After vacuumdrying at $110^{\circ} \mathrm{C}$ for $10 \mathrm{~h}$, the electrodes were cut into circular pieces with a diameter of $12 \mathrm{~mm}$, which were used as anodes for the assembled cell. The mass loading of the electrodes was $1.5 \mathrm{mg} \mathrm{cm}^{-2}$. The electrolytes for comparison were 1 $\mathrm{M} \mathrm{NaCF}_{3} \mathrm{SO}_{3}$ dissolved in a mixture of $\mathrm{EC}$ and $\mathrm{DEC}$ (volume ratio $=1: 1$ ), and $1 \mathrm{M}$ $\mathrm{NaCF}_{3} \mathrm{SO}_{3}$ dissolved in diglyme. Using these electrodes and electrolytes with pure sodium foils as counter electrodes and Whatman GF/D glass fibers as separators, 2032-type coin cells were assembled in an argon-filled glove box with oxygen and moisture contents below $0.1 \mathrm{ppm}$. Galvanostatic charge-discharge tests were conducted on a LAND CT2001 battery program controlling system at different current densities with a voltage window of $0.005-2.5 \mathrm{~V}$ vs. $\mathrm{Na} / \mathrm{Na}^{+}$.

Cyclic voltammetry. CV measurements were conducted using an electrochemical workstation (VMP3, Bio Logic, France) at scanning rates from $0.1 \mathrm{mV} \mathrm{s}^{-1}$ to $10 \mathrm{mV} \mathrm{s}^{-1}$ in the voltage range of $0.005-2.5 \mathrm{~V}$ vs. Na/Na+ at room temperature.

Electrochemical Impedance Spectroscopy. All EIS measurements were carried out using a PARSTAT 4000 electrochemical workstation, using a frequency range of $10^{5} \mathrm{~Hz}$ to $100 \mathrm{mHz}$ and an $\mathrm{AC}$ voltage amplitude of $10 \mathrm{mV}$. The cell temperature was controlled in a temperature-controlled chamber (Linkam Scientific) and was varied between 0 and $40^{\circ} \mathrm{C}\left( \pm 0.1{ }^{\circ} \mathrm{C}\right)$ in steps of $10^{\circ} \mathrm{C}$ using a nitrogen-gas flow and electronic heaters (Linkam Scientific) for the temperature-dependent experiments.

In operando Raman spectroscopy and in situ XRD. Raman spectra acquisition during cell operation has been described in detail elsewhere and is schematically shown in Supplementary Figure $5\left(\right.$ ref. ${ }^{39}$ ). For the measurements, a special electrode was used which was prepared by mixing the active materials with super $\mathrm{P}$ and $5 \mathrm{wt} \%$ PTFE in water to obtain a homogenous slurry. The final content of the active materials was $80 \mathrm{wt} \%$. The slurry was rolled into a thin film, which was then pressed onto a stainless-steel mesh. A delicate battery cell with a quartz window on the top was used (Supplementary Figure 5). The Raman spectra were recorded on a MicroRaman system (LabRAM HR spectrometer, Horiba) with an Olympus BX microscope and an argon ion laser $(532.05 \mathrm{~nm})$. Each spectrum was acquired for $20 \mathrm{~s}$. The galvanostatic discharge of the cell was controlled by an electrochemical workstation (PARSTAT 4000). A similar battery cell to that used for the in operando Raman spectroscopy was designed, replacing the quartz window with a Kapton film window to perform the in situ XRD measurements (Supplementary Figure 8).

Surface characterization. XPS survey scan analyses were conducted on a PHI 5000 VersaProbe II spectrometer using a monochromatic Al K $\mathrm{X}_{\alpha}$-ray $(1486.6 \mathrm{eV})$ source. High-resolution XPS analyses were carried out using an ESCALAB 250Xi spectrometer with a $\mathrm{Mg} \mathrm{K}_{\alpha} \mathrm{X}$-rays source, in order to eliminate the interferences of the Na Auger peak with the oxygen 1s photoelectron line and the Ti Auger peak with the $\mathrm{Na}$ 1s peak. The batteries were disassembled in a glove box after 10 discharge-charge cycles at a rate of $100 \mathrm{~mA} \mathrm{~g}^{-1}$, and the anodes were washed several times with the related solvent, i.e., dimethyl carbonate (DMC) for EC/DEC and dimethoxyethane (DME) for diglyme. After drying, the anodes were transferred to a vacuum box and then transferred into the XPS chamber. Samples were ion-etched using $2 \mathrm{kV}$ Ar ions over $2 \times 3 \mathrm{~mm}^{2}$ with an etching rate of approximately $4.3 \mathrm{~nm} \mathrm{~min}{ }^{-1}$. Spectra were charge corrected to the main line of the carbon 1s spectrum (adventitious carbon) and set to a BE of $284.8 \mathrm{eV}$ (Supplementary Figure 21).

\section{Data availability}

The data that support the findings of this study are available within the article and its Supplementary Information files. All other relevant data supporting the findings of this study are available from the corresponding authors upon reasonable request.

Received: 9 July 2018 Accepted: 11 January 2019

Published online: 13 February 2019 


\section{References}

1. Van Noorden, R. The rechargeable revolution: a better battery. Nature 507, 26-28 (2014).

2. Vaalma, C., Buchholz, D., Weil, M. \& Passerini, S. A cost and resource analysis of sodium-ion batteries. Nat. Rev. Mater. 3, 18013 (2018).

3. Li, J. et al. Significantly improved sodium-ion storage performance of CuS nanosheets anchored into reduced graphene oxide with ether-based electrolyte. ACS Appl. Mater. Interfaces 9, 2309-2316 (2017).

4. Huang, H., Wu, H. H., Wang, X., Huang, B. \& Zhang, T. Y. Enhancing sodium ionic conductivity in tetragonal- $\mathrm{Na}_{3} \mathrm{PS}_{4}$ by halogen doping: a first principles investigation. Phys. Chem. Chem. Phys. 20, 20525-20533 (2018).

5. Li, Y. M. et al. Recent advances of electrode materials for low-cost sodium-ion batteries towards practical application for grid energy storage. Energy Storage Mater. 7, 130-151 (2017).

6. Masse, R. C., Uchaker, E. \& Cao, G. Z. Beyond Li-ion: electrode materials for sodium- and magnesium-ion batteries. Sci. China Mater. 58, 715-766 (2015).

7. Slater, M. D., Kim, D., Lee, E. \& Johnson, C. S. Sodium-ion batteries. Adv. Funct. Mater. 23, 947-958 (2013).

8. Kundu, D., Talaie, E., Duffort, V. \& Nazar, L. F. The emerging chemistry of sodium ion batteries for electrochemical energy storage. Angew. Chem. Int. Ed. Engl. 54, 3431-3448 (2015).

9. Zhang, J. et al. Achieving superb sodium storage performance on carbon anodes through an ether-derived solid electrolyte interphase. Energy Environ. Sci. 10, 370-376 (2017).

10. $\mathrm{Hu}, \mathrm{Z}$. et al. Pyrite $\mathrm{FeS}_{2}$ for high-rate and long-life rechargeable sodium batteries. Energy Environ. Sci. 8, 1309-1316 (2015).

11. Su, D. W., Kretschmer, K. \& Wang, G. X. Improved electrochemical performance of Na-ion batteries in ether-based electrolytes: a case study of ZnS nanospheres. Adv. Energy Mater. 6, 1501785 (2016).

12. Cohn, A. P., Share, K., Carter, R., Oakes, L. \& Pint, C. L. Ultrafast solventassisted sodium ion intercalation into highly crystalline few-layered graphene. Nano. Lett. 16, 543-548 (2016).

13. Kim, H. et al. Sodium storage behavior in natural graphite using ether-based electrolyte systems. Adv. Funct. Mater. 25, 534-541 (2015).

14. Zhang, J., et al. Ethers illume sodium-based battery chemistry: uniqueness, surprise, and challenges. Adv. Energy Mater. 8, 1801361 (2018).

15. Wang, C. C., Wang, L. B., Li, F. J., Cheng, F. Y. \& Chen, J. Bulk bismuth as a high-capacity and ultralong cycle-life anode for sodium-ion batteries by coupling with glyme-based electrolytes. Adv. Mater. 29, 1702212 (2017).

16. Seh, Z. W., Sun, J., Sun, Y. M., \& Cui, Y. A highly reversible room-temperature sodium metal anode. ACS Cent. Sci. 1, 449-455 (2015).

17. Larcher, D. \& Tarascon, J. M. Towards greener and more sustainable batteries for electrical energy storage. Nat. Chem. 7, 19-29 (2015).

18. Munoz-Marquez, M. A. et al. Na-ion batteries for large scale applications: review on anode materials and solid electrolyte interphase formation. Adv. Energy Mater. 7, 1700463 (2017).

19. $\mathrm{Xu}$, Y. et al. Nanocrystalline anatase $\mathrm{TiO}_{2}$ : a new anode material for rechargeable sodium ion batteries. Chem. Commun. 49, 8973-8975 (2013).

20. Lunell, S., Stashans, A., Ojamae, L., Lindstrom, H. \& Hagfeldt, A. Li and Na diffusion in $\mathrm{TiO}_{2}$ from quantum chemical theory versus electrochemical experiment. J. Am. Chem. Soc. 119, 7374-7380 (1997).

21. $\mathrm{Wu}, \mathrm{L}$. M. et al. Unfolding the mechanism of sodium insertion in anatase $\mathrm{TiO}_{2}$ nanoparticles. Adv. Energy Mater. 5, 1401142 (2015).

22. Li, W. et al. A reversible phase transition for sodium insertion in anatase $\mathrm{TiO}_{2}$. Chem. Mater. 29, 1836-1844 (2017).

23. Zhang, G. Q., Wu, H. B., Song, T., Paik, U. \& Lou, X. W. $\mathrm{TiO}_{2}$ hollow spheres composed of highly crystalline nanocrystals exhibit superior lithium storage properties. Angew. Chem. Int. Ed. Engl. 53, 12590-12593 (2014).

24. Chen, $\mathrm{C}$. et al. $\mathrm{Na}(+)$ intercalation pseudocapacitance in graphene-coupled titanium oxide enabling ultra-fast sodium storage and long-term cycling. Nat. Commun. 6, 6929 (2015)

25. Aravindan, V., Lee, Y. S., Yazami, R. \& Madhavi, S. $\mathrm{TiO}_{2}$ polymorphs in 'rocking-chair' Li-ion batteries. Mater. Today 18, 345-351 (2015).

26. Longoni, G. et al. Shape-controlled $\mathrm{TiO}_{2}$ nanocrystals for Na-ion battery electrodes: the role of different exposed crystal facets on the electrochemical properties. Nano Lett. 17, 992-1000 (2017).

27. Wu, L. M., Buchholz, D., Bresser, D., Chagas, L. G. \& Passerini, S. Anatase $\mathrm{TiO}_{2}$ nanoparticles for high power sodium-ion anodes. J. Power Sources 251, 379-385 (2014).

28. Dahbi, M., Yabuuchi, N., Kubota, K., Tokiwa, K. \& Komaba, S. Negative electrodes for Na-ion batteries. Phys. Chem. Chem. Phys. 16, 15007-15028 (2014).

29. Tahir, M. N. et al. Extraordinary performance of carbon-coated anatase $\mathrm{TiO}_{2}$ as sodium-ion anode. Adv. Energy Mater. 6, 1501489 (2016).

30. Xiong, Y., Qian, J., Cao, Y., Ai, X. \& Yang, H. Electrospun $\mathrm{TiO}_{2} / \mathrm{C}$ nanofibers as a high-capacity and cycle-stable anode for sodium-ion batteries. ACS Appl. Mater. Interfaces 8, 16684-16689 (2016).

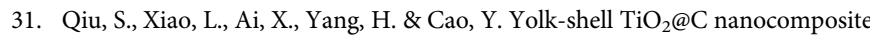
as high-performance anode material for sodium-ion batteries. ACS Appl. Mater. Interfaces 9, 345-353 (2017).

32. Shi, X. D. et al. Anatase $\mathrm{TiO}_{2} @ \mathrm{C}$ composites with porous structure as an advanced anode material for $\mathrm{Na}$ ion batteries. J. Power Sources 330, 1-6 (2016).

33. Chen, J. et al. Pinecone-like hierarchical anatase $\mathrm{TiO}_{2}$ bonded with carbon enabling ultrahigh cycling rates for sodium storage. J. Mater. Chem. A 4, 12591-12601 (2016)

34. Ni, J. et al. Self-supported nanotube arrays of sulfur-doped $\mathrm{TiO}_{2}$ enabling ultrastable and robust sodium storage. Adv. Mater. 28, 2259-2265 (2016)

35. Wang, B. et al. Boron-doped anatase $\mathrm{TiO} 2$ as a high-performance anode material for sodium-ion batteries. ACS Appl. Mater. Interfaces 8, 16009-16015 (2016).

36. Liu, S. A., Cai, Z. Y., Zhou, J., Pan, A. Q. \& Liang, S. Q. Nitrogen-doped $\mathrm{TiO}_{2}$ nanospheres for advanced sodium-ion battery and sodium-ion capacitor applications. J. Mater. Chem. A 4, 18278-18283 (2016).

37. Zhang, J. et al. The interplay of oxygen functional groups and folded texture in densified graphene electrodes for compact sodium-ion capacitors. Adv. Energy Mater. 8, 1702395 (2018)

38. Dinh, C. T., Nguyen, T. D., Kleitz, F. \& Do, T. O. Shape-controlled synthesis of highly crystalline titania nanocrystals. ACS Nano 3, 3737-3743 (2009).

39. $\mathrm{Li}, \mathrm{K}$. et al. Ultrafast-charging and long-life li-ion battery anodes of $\mathrm{TiO}_{2}-\mathrm{B}$ and anatase dual-phase nanowires. ACS Appl. Mater. Interfaces $\mathbf{9}$, 35917-35926 (2017)

40. $\mathrm{Li}, \mathrm{K}$. et al. Discovering a first-order phase transition in the $\mathrm{Li}-\mathrm{CeO}_{2}$ system Nano Lett. 17, 1282-1288 (2017).

41. Bella, F. et al. Unveiling the controversial mechanism of reversible Na storage in $\mathrm{TiO}_{2}$ nanotube arrays: amorphous versus anatase $\mathrm{TiO}_{2}$. Nano Res. 10 2891-2903 (2017).

42. Yan, D. et al. Improved sodium-ion storage performance of $\mathrm{TiO}_{2}$ nanotubes by $\mathrm{Ni}^{2+}$ doping. J. Mater. Chem. A 4, 11077-11085 (2016).

43. Das, S. K. et al. Graphene mediated improved sodium storage in nanocrystalline anatase $\mathrm{TiO}_{2}$ for sodium ion batteries with ether electrolyte. Chem. Commun. 52, 1428-1431 (2016).

44. Wang, J., Polleux, J., Lim, J. \& Dunn, B. Pseudocapacitive contributions to electrochemical energy storage in $\mathrm{TiO}_{2}$ (anatase) nanoparticles. J. Phys. Chem. C 111, 14925-14931 (2007).

45. $\mathrm{Li}, \mathrm{S}$. M. et al. Alternating voltage induced ordered anatase $\mathrm{TiO}_{2}$ nanopores: an electrochemical investigation of sodium storage. J. Power Sources 336, 196-202 (2016)

46. Barsoukov, E. et al. Comparison of kinetic properties of $\mathrm{LiCoO}_{2}$ and $\mathrm{LiTi}_{0.05} \mathrm{Mg}_{0.05} \mathrm{Ni}_{0.7} \mathrm{Co}_{0.2} \mathrm{O}_{2}$ by impedance spectroscopy. Solid State Ion. 161, 19-29 (2003).

47. Busche, M. R. et al. Dynamic formation of a solid-liquid electrolyte interphase and its consequences for hybrid-battery concepts. Nat. Chem. 8, 426-434 (2016).

48. Soto, F. A., Marzouk, A., El-Mellouhi, F. \& Balbuena, P. B. Understanding ionic diffusion through SEI components for lithium-ion and sodium-ion batteries: insights from first-principles calculations. Chem. Mater. 30, 3315-3322 (2018)

49. Choudhury, S. et al. Designing solid-liquid interphases for sodium batteries. Nat. Commun. 8, 898 (2017).

50. Munoz-Marquez, M. A. et al. Composition and evolution of the solidelectrolyte interphase in Na2Ti3O7 electrodes for Na-ion batteries: XPS and Auger parameter analysis. ACS Appl. Mater. Interfaces 7, 7801-7808 (2015).

51. Pan, Y. et al. Investigation of the solid electrolyte interphase on hard carbon electrode for sodium ion batteries. J. Electroanal. Chem. 799, 181-186 (2017).

52. $\mathrm{Bi}, \mathrm{X}$. X. et al. Investigating dendrites and side reactions in sodium-oxygen batteries for improved cycle lives. Chem. Commun. 51, 7665-7668 (2015).

53. Dahbi, M. et al. Black phosphorus as a high-capacity, high-capability negative electrode for sodium-ion batteries: investigation of the electrode/interface. Chem. Mater. 28, 1625-1635 (2016).

54. Eshetu, G. G. et al. Impact of the electrolyte salt anion on the solid electrolyte interphase formation in sodium ion batteries. Nano Energy 55, 327-340 (2019).

55. Zhou, M. et al. Amorphous $\mathrm{TiO}_{2}$ inverse opal anode for high-rate sodium ion batteries. Nano Energy 31, 514-524 (2017).

56. Chen, J. et al. Black anatase titania with ultrafast sodium-storage performances stimulated by oxygen vacancies. ACS Appl. Mater. Interfaces 8, 9142-9151 (2016).

57. $\mathrm{Li}, \mathrm{Y}$. et al. Excellent sodium storage performance of carbon-coated $\mathrm{TiO}_{2}$ assisted with electrostatic interaction of surfactants. J. Power Sources 361, 326-333 (2017)

58. Oh, S. M. et al. High electrochemical performances of microsphere C- $\mathrm{TiO}(2)$ anode for sodium-ion battery. ACS Appl. Mater. Interfaces 6, 11295-11301 (2014). 
59. Su, D. W., Dou, S. X. \& Wang, G. X. Anatase $\mathrm{TiO}_{2}$ : better anode material than amorphous and rutile phases of $\mathrm{TiO}_{2}$ for Na-ion batteries. Chem. Mater. 27, 6022-6029 (2015).

60. Kim, K. T. et al. Anatase titania nanorods as an intercalation anode material for rechargeable sodium batteries. Nano Lett. 14, 416-422 (2014).

\section{Acknowledgements}

This work was supported by the National Science Fund for Distinguished Young Scholars, China (No. 51525204), the National Natural Science Foundation of China (Nos. U1601206, 51772164, and U1710256), Local Innovative and Research Teams Project of Guangdong Pearl River Talents Program (2017BT01N111), the Shenzhen Technical Plan Project (Nos. JCYJ20170412171630020 and JCYJ20170412171359175), the 111 project (No. D16002) from the State Administration of Foreign Experts Affairs and the Ministry of Education, PRC, and the General Research Fund (No. 15210718) from Hong Kong Research Grants Council. The authors thank Mr. Kun Qian for his assistance in the in situ XRD measurements.

\section{Author contributions}

Q.H.Y., T.Y.Z., and L.M.Z. managed the project and guided the research; K.K.L. and J.Z. contributed equally to the paper; D.M.L., B.H.L., Y.B.H., and F.Y.K. participated in the experiments; W.L., D.W.W., and S.S. were involved in the discussions; K.K.L. and J.Z. wrote the manuscript with the supervision of Q.H.Y., T.Y.Z., and L.M.Z., and all authors have approved the final manuscript.

\section{Additional information}

Supplementary Information accompanies this paper at https://doi.org/10.1038/s41467019-08506-5
Competing interests: The authors declare no competing interests.

Reprints and permission information is available online at http://npg.nature.com/ reprintsandpermissions/

Journal peer review information: Nature Communications thanks the anonymous reviewers for their contribution to the peer review of this work.

Publisher's note: Springer Nature remains neutral with regard to jurisdictional claims in published maps and institutional affiliations.

(c) (i) Open Access This article is licensed under a Creative Commons Attribution 4.0 International License, which permits use, sharing, adaptation, distribution and reproduction in any medium or format, as long as you give appropriate credit to the original author(s) and the source, provide a link to the Creative Commons license, and indicate if changes were made. The images or other third party material in this article are included in the article's Creative Commons license, unless indicated otherwise in a credit line to the material. If material is not included in the article's Creative Commons license and your intended use is not permitted by statutory regulation or exceeds the permitted use, you will need to obtain permission directly from the copyright holder. To view a copy of this license, visit http://creativecommons.org/ licenses/by/4.0/.

(C) The Author(s) 2019 